\title{
Preoblikovanje identitet v Temnih skrivnostih avstralske staroselske pesnice Jeanine Leane
}

\section{Danica Čerče}

Filozofska fakulteta UL, Oddelek za anglistiko in amerikanistiko, Aškerčeva 2, 1000 Ljubljana, Slovenija

https://orcid.org/0000-0002-2135-3003

danica.cerce@ff.uni-lj.si

Prispevek obravnava sodobno avstralsko staroselsko poezijo in še posebej pesniško zbirko Temne skrivnosti Jeanine Leane. Z razcvetom sredi osemdesetih let 20. stoletja je avstralska staroselska poezija postala pomemben medij za artikulacijo kritičnih misli staroselcev. Z edukativno in zdravilno vlogo, ki jo opravlja s poseganjem v navidezno neukinljiva binarna nasprotja avtoritativnega diskurza, predstavitvijo zamolčane avstralske zgodovine in zahtevo po spremembah, je ta poezija postala del produkcije, ki je bila do nedavnega v izključni domeni Evropejcev. Z izhodiščem v kritiški misli o pomembni družbeni vlogi književnih besedil in opirajoč se na kritiko koncepta evropocentrizma, pričujoči članek raziskuje, kako Leane s problematizacijo stereotipov kot glavne strategije kolonialnega diskurza intervenira v javno dinamiko rasne separacije in destabilizira domneve o legitimnosti reprodukcije kolonialnih razlik. Končna ugotovitev je, da njen pesniški svet opravlja osebno in kolektivno opolnomočenje avstralskih staroselcev in ustvarja pogoje za boljšo kvaliteto medrasnih odnosov.

Ključne besede: avstralska književnost / staroselci / staroselska poezija / Leane, Jeanine: Temne skrivnosti / kulturna identiteta / kulturni stereotipi / evropocentrizem

Ni še dolgo od tega, ko so bili avstralski staroselski umetniki marginalizirani glasovi. V književnosti je v poznih sedemdesetih letih 20. stoletja sloves kritiško priznanih avtorjev imela samo peščica, med njimi David Unaipon v prozi, Kath Walker (bolj znana po svojem plemenskem imenu Oodgeroo) in Lionel Fogarty v poeziji ter Kevin Gilbert in Jack Davis v dramatiki. Pomemben premik v tem smislu se zgodi v osemdesetih letih 20. stoletja s pravim razcvetom staroselske ustvarjalnosti v okviru vsesplošnega boja proti kolonialni avtoriteti. Vzroke za povečano umetniško produkcijo avstralskih staroselcev najbrž lahko pripišemo tudi veliki odmevnosti in mednarodnemu uspehu avtobiografskega 
romana Sally Morgan, My Place (1987). ${ }^{1} \mathrm{~V}$ vseh žanrih so začela nastajati umetniško priznana dela, ki so terjala spremembe na avstralski politični in družbeni sceni. Pri tem je imela še posebej pomembno vlogo poezija, saj je največje število prvotnih prebivalcev izbralo prav ta medij za izraz svojih kritičnih misli. Tako kot prvo knjigo staroselske poezije izpod peresa že omenjene Oodgeroo, ki že z naslovom Gremo! (1964) nakazuje protest, močna politično aktivistična nota prežema tudi poezijo $s$ kasnejšim datumom nastanka, pod katero se podpisujejo Colin Thomas Johnson, bolj znan kot Mudrooroo, Lisa Bellear, Romaine Moreton, Alf Taylor, Michael Smith, Monica Claire, John Muk Muk Burke, Jeanine Leane in drugi. Z razkrivanjem aktualnih žarišč krivic nad staroselskim prebivalstvom in njihovega položaja drugorazrednih državljanov, ubeseditvijo zamolčane preteklosti in nasprotovanjem kolonialnim identitetnim konstruktom ta poezija artikulira diskurz »osveščenih antagonistov«, kot Edward Said imenuje tiste, ki se zoperstavijo in ogrozijo obstoj sistema, $v$ katerem jim je določena vloga podrejenih (335), in bralcem odpira nove poglede.

Drama kolonialnih odnosov in post-kolonialnega nasprotovanja in spreminjanja teh odnosov se je v veliki meri odvijala v okviru reprezentacije in protesta (Ashcroft, Griffiths in Tiffin 85). V obeh primerih je imela književnost pomembno vlogo. Evropska besedila so neevropske subjekte postavljala v evropske mentalne okvire in pričakovanja in njihovo drugačnost prikazovala kot pomanjkljivost in izgovor za represijo. Literarni protest proti takšnim kolonialnim reprezentacijam in ideologijam, ki so jih razširjale in postavile za normo, se je realiziral na različne načine, vselej pa z namenom destabilizacije ustaljenih vzorcev, ki slonijo na avtoritativnem diskurzu oziroma predpostavkah o rasni superiornosti enih in posledični inferiornosti drugih.

Kritiki, ki ne sprejemajo hierarhije med kulturami kot objektivnega dejstva in posledične upravičenosti delitve na tako imenovane 'višje' in 'nižje kulture', poudarjajo, da je konstruiranje identitete staroselcev kot inferiorne družbene skupine predstavljalo vitalni del pri vzpostavitvi in ohranjanju "družbene pogodbe, $v$ kateri so izključevanje, neenakost in teza o večvrednosti bele rase glavne premise (Mills 445). S kolonialnim diskurzom vzpostavljena identiteta staroselcev seveda ni odraz resničnosti, ampak je samo pripravni politični konstrukt. Zavračanje sodb, izpeljanih po logiki dominantne zgodovinske naracije, je tudi osnovna izhodiščna matrica literarnega ustvarjanja Jeanine Leane, pripadnice

${ }^{1}$ Delo je na voljo tudi v slovenskem prevodu Tamare Bosnič. Z naslovom Vobjem korenin je leta 2007 izšlo pri založbi Miš. 
plemena Wiradjuri v Novem južnem Walesu. Ob predstavitvi njene pesniške zbirke Temne skrivnost (Dark Secrets) ${ }^{2}$ se bom zato ukvarjala z vprašanjem, kako pesničina družbenokritična retorika izziva utvaro o vsestranski superiornosti bele rase $\mathrm{v}$ odnosu do vseh 'drugih' in $s$ tem destabilizira obstoječo naturalizirano hierarhijo. $Z$ izhodiščem $v$ tezi o pomembni vlogi literarnih besedil pri oblikovanju oziroma preoblikovanju identitet posameznikov, družbenih skupin in skupnosti (Juvan, Literarna 29), bom poskušala pokazati, da staroselska poezija z razblinjanjem lažnih predpostavk, ustvarjenih na osnovi miselne paradigme dualizma, ki določenim družbenim skupinam in kulturam pripisuje status inferiornosti ali superiornosti, staroselcem vrača dostojanstvo in družbeno upanje. Kot ugotavlja avstralski sociolog Ghassan Hage, se polnopravna udeležba $\mathrm{v}$ vseh političnih in civilnih sferah avstralske družbe še vedno zdi izključna domena belcev (22). Moje branje omenjene pesniške zbirke se torej ne osredotoča na literarnost kot osrednji objekt raziskave in vrednotenja; bolj kot $s$ tem se bom ukvarjala $\mathrm{z}$ "javnim življenjem" te poezije, kot družbenopolitično angažiranost literarnih del imenujeta David Carter in Kay Ferres (140), natančneje $\mathrm{z}$ vprašanjem, kako deluje kot "oblika javnega dobrega" (Gonzales in Agostini xvi).

\section{"Književnost z razlogom»}

Kljub nasprotovanju tistih, ki se zavzemajo za "estetsko avtonomijo umetnosti« in zavračajo njeno vpetost v kakršnekoli idejne in ideološke okvire (Barbo 59), ni mogoče zanikati političnih implikacij književnih besedil in njihove tesne povezanosti s politiko časa, $\mathrm{v}$ katerem nastanejo (Levine 383). Kot »eno od oblik oziroma lokacij sporazumevanja [...], preko katerih se vzdržuje in prerazporeja tudi politična moč« (Juvan, Literarna 107), literarno delo namreč lahko podpira in krepi strukture nadvlade ali pa omaja njihovo moč. Zahodni literarni kanon ni imel pomembne vloge samo $\mathrm{v}$ politiki zahodnega imperializma in zatiranja "manjvrednih" ras in kultur, kot je s številnimi primeri dokazal Said (npr. v delu Culture and Imperialism), ampak tudi pri »razkroju vladavine moči« (Levine 384). Res je, kot ugotavlja Marko Juvan, da je danes vloga literarnih besedil manjša $v$ primerjavi s sporočili množičnih

${ }^{2}$ Slovenski prevod naslovne pesmi zbirke in kratek sestavek o pesnici izpod peresa avtorice pričujočega prispevka sta bila objavljena v Delu 30. aprila 2013 (Čerče, »Ko je bila«). 
medijev, v preteklosti pa so imela pomembno »ideološko-formativno vlogo" (Juvan, Literarna 29). Naj mimogrede omenim, da so v političnih režimih, ki so delovali v imenu marksizma in leninizma, književnost pojmovali kot "osrednjo gibalno silo družbenih sprememb« (Lukács 164). ${ }^{3}$

Avstralska staroselska književnost je vsekakor »književnost $\mathrm{z}$ razlogom ", če uporabim izraz, s katerim Jace Weaver označuje ameriško staroselsko književnost (44). Zaznamuje jo namreč podobno neprikrito nasprotovanje institucionalnim in zgodovinskim procesom, ki so omogočili vzpostavitev in ohranitev dominacije Evropejcev in spremljajočo politično, ekonomsko in kulturno subordinacijo prvotnega prebivalstva. Osredinjena na manjšinsko prebivalstvo kljubuje literarnim tradicijam »imperija « ${ }^{4}$ in literarnemu subjektivizmu teh tradicij ter izpodbija legitimnost evropocentrične epistemologije oziroma »eksplicitnega poudarjanja inferiornosti vseh, ki se nahajajo zunaj evropskih kategorij védenja in identitete" (Mignolo 386). V tem prizadevanju je podobna postkolonialnim književnostim Latinske Amerike, Karibskega otočja, Podsaharske Afrike, južne Azije in nekaterim drugim, ki intervenirajo v lažne domneve o beli rasi kot »konstantno privilegirani kategoriji» (Suleri 111). Prikrajšani za vrsto državljanskih pravic so avstralski staroselci postali dejavniki umetniške produkcije, ki je do nedavnega veljala za domeno Evropejcev. S svojo predstavitvijo zgodovinskih dogodkov pri bralcih razblinjajo in zavračajo obstoječe vrednostne predstave in vzorce, postavljene za ohranitev ločnice med tistimi s politično močjo in tistimi, ki te moči nimajo. Pri edukaciji bralcev začnejo kar s prihodom Britancev v Avstralijo: belci ga razumejo kot naselitev, staroselci kot invazijo. Že to nakazuje, da se staroselski avtorji drzno lotevajo vsebin, s katerimi se dotlej avstralska književnost ni ukvarjala.

Do nedavnega so namreč o avstralski preteklosti in z zelo opaznim stališčem o deficienci staroselcev pisali predvsem mainstreamski avstralski avtorji, od začetka osemdesetih let pa tematizacija avstralske družbenozgodovinske situacije vznemirja in zaposluje številne staroselske ustvarjalce. $\mathrm{V}$ političnem sistemu, v katerem so staroselci skoraj neslišani in $\mathrm{v}$ katerem uradna zgodovina o marsičem molči, je namreč književnost tisti medij, ki jim daje glas, pravi Anita Heiss, pisateljica, pesnica, aktivistka in akademikinja iz plemena Wiradjuri (2). Ob tem velja omeniti, da je ena najbolj konsistentnih preokupacij sodobne avstralske književnosti teža preteklosti, v središču avstralske zavesti pa

\footnotetext{
${ }^{3} \mathrm{O}$ politizaciji književnosti pišem v Čerče, "Ideološko«.

${ }^{4}$ Glej študijo Ashcroft, Griffiths in Tiffin.
} 
dvojna travma, in sicer Avstralija kot britanska kazenska kolonija, kot je bila njena prva funkcija, in pogubni vpliv invazije in naselitve belcev na staroselsko prebivalstvo (Crow in Banfield 29). Obe temi sta povezani z nasiljem, izgonom, razlastitvijo in brutalno neobčutljivostjo do sočloveka. Toda medtem ko je bila prva že izčrpno raziskana iz najrazličnejših zornih kotov, je bila druga vsaj do nedavnega v veliki meri prezrta in celo prikrita. Bela Avstralija se namreč dolgo ni bila pripravljena soočiti $s$ temno stranjo svoje zgodovine, saj njeno ravnanje ni bilo v skladu $s$ (samo)podobo države kot visoko moralne skupnosti. Svoj odnos do staroselcev je zato vztrajno pometala pod težko preprogo pozabe (Leane, "Aboriginal«34).

Napredni del avstralske politike je konec prejšnjega stoletja vendarle prekinil tradicijo prelaganja krivde, neposrednega zanikanja in molka ter objavil za mnoge šokantna poročila o naporih staroselcev za kulturno in biološko preživetje. Temu je leta 2008 sledilo še javno opravičilo takratnega predsednika vlade Kevina Rudda. Staroselcem je priznal najdaljšo nepretrgano zgodovino $\mathrm{v}$ Avstraliji in to gesto vlade, $\mathrm{s}$ katero je ovrgel njeno lažno filozofijo zgodovinske kontinuitete, ${ }^{5}$ označil za novo poglavje $\mathrm{v}$ zgodovini avstralske celine in za začetek procesa zdravljenja naroda (Johnston). Kot bom z nekaj statističnimi podatki osvetlila v nadaljevanju, pa nova stvarnost ni prekinila potrebe staroselcev po nadaljnjem izrazu kolektivnih prizadevanj za vsestransko uveljavitev in dekonstrukcijo zgodovinskega spomina, kot ga je v literarna dela in zavest prebivalcev mnogo let vtiskovala bela Avstralija. Slednja s svojim »ideološkim konstruktom «, kot je diskurz, ki postavlja v center Evropo in Evropejce in jim lažno potrjuje superiornost nad ostalim svetom označil Samir Amin (5), še vedno ni zmožna v celoti preseči stereotipnih predstav o staroselcih in odpraviti njihovega drugorazrednega družbenega statusa.

\section{Konture aktualnega družbenega okolja in zgodovinskega dogajanja v Avstraliji}

Zbirka Temne skrivnosti (2010) ni samo pesniški prvenec Jeanine Leane, ampak je tudi njeno prvo literarno delo. Že v letu izida je zanjo prejela nagrado za najboljšo staroselsko pesniško zbirko. Leto kasneje, po

${ }^{5}$ Avstralska celina ob prihodu belcev ni bila terra nullius oziroma nikogaršnja zemlja, kot so trdili britanski kolonizatorji in s tem upravičevali okupacijo. V času britanske invazije (leta 1788) je na ozemlju Avstralije živelo med 600.000 in 1.000.000 staroselcev, njihovo število pa se je v pičlih sto letih zmanjšalo na 80.000. 
izidu romanesknega prvenca Purple Threads (Škrlatne niti), je Leanova prejela tudi nagrado za najboljše staroselsko prozno delo. Nagrajena je bila še večkrat, nazadnje leta 2017 z nagrado Oodgeroo Noonuccal za poezijo, trikrat pa nominirana za prestižno nagrado Davida Unaipona. ${ }^{6}$ Leanova je tudi uspešna raziskovalka na Avstralskem inštitutu za staroselske študije v Canberri in predavateljica avstralske staroselske književnosti in kreativnega pisanja na Univerzi v Melbournu, na vseh področjih svojega delovanja pa opaža, da imajo ne-staroselci zelo omejeno, enostransko podobo o manjšinski skupnosti, takšno, kot so jo pridobili tudi z branjem del mainstreamskih avtorjev. Stik s staroselsko književnostjo, ki avstralske prebivalce in zgodovinsko dogajanje slika v drugačni osvetljavi, je zato zanje velik izziv (Leane, »Aboriginal« 32).

Za boljše razumevanje pesničine ustvarjalne vneme, ki se vklaplja $\mathrm{v}$ kolektivno potrebo staroselcev po nadaljnjem osvetljevanju zgodovinskih situacij in družbenih krivic, je potrebno spomniti na nekaj dejstev in statističnih podatkov. Ti potrjujejo aktualnost teorije Michela Foucaulta o neposredni povezavi med védenjem, politično močjo in mestom subjekta. Številni indici namreč pričajo, da avstralski staroselci kljub postopni spremembi avstralske diskriminatorne zakonodaje po letu 1967, ko so dobili avstralsko državljanstvo, še vedno nimajo ustreznega diskurznega in materialnega prostora $\mathrm{v}$ avstralski družbi in zgodovini. Anne Brewster trdi, da je sodobna multikulturna Avstralija v razmerju do staroselcev obdržala »nadvlado brez hegemonije« (59), pri čemer uporabi izraz, $s$ katerim Ranajit Guha opredeli zgodnjo fazo indijske postkolonialne zgodovine (glej Guha). Za avstralske staroselce uradno državljanstvo namreč ni postalo tudi resnično državljanstvo, saj je Avstralija ohranila »konstituanto, ki jim nikoli ni priznala popolne suverenosti« (Brewster, »Engaging« 60).

Da staroselci, zdesetkani v procesu genocida, razlastitve, prisilnega dela in odvzema otrok, ${ }^{7}$ živijo $\mathrm{v}$ "politično ohranjenem subalternem položaju (Mignolo 386) in so najbolj ogroženi segment med prebivalci Avstralije, dokazujejo tudi podatki o visoki stopnji nezaposlenosti, slabi zdravniški oskrbi in akutnem pomanjkanju izobrazbe. Samo vsak

${ }^{6}$ David Unaipon je leta 1929 izdal zbirko mitov in legend (Native Legends), ki velja za prvo delo avstralskega staroselskega avtorja, Oodgeroo pa je avtorica prve staroselske pesniške zbirke (We Are Going!). Izšla je leta 1964.

${ }^{7}$ V Avstraliji živi 23 milijonov prebivalcev, od tega je le še 470.000 oz. dobra $2 \%$ staroselcev. Leta 1886 je bil sprejet zakon (Half-Caste Act), ki je pristojnim dovoljeval nasilni odvzem otrok mešancev (tistih z vsaj $25 \%$ staroselske krvi) iz staroselskih družin in njihovo prisilno asimilacijo v belskih družinah. V času trajanja tega zakona (do 1970) je bilo nasilno odvzetih več kot 100.000 otrok. 
peti med njimi ima srednješolsko izobrazbo, zato so večinoma zaposleni kot nekvalificirani delavci. Delež bolnikov z diabetesom, boleznimi srca in ožilja in depresijo je med staroselci neprimerno večji kot med belimi Avstralci. Veliko pogostejša je tudi smrt novorojenčkov, večja je odvisnost od drog in alkohola, več je nasilja. ${ }^{8}$ Širša avstralska javnost se je $z$ razsežnostjo alkoholizma in $s$ tem povezanim nasiljem in umrljivostjo seznanila šele z izidom antropoloških raziskav v prvem desetletju novega tisočletja. Še posebej pomembni v tem smislu sta raziskavi Petra Suttona in Louisa Nowre. Zaradi podobnega sistemskega privilegiranja belcev v družbenih, ekonomskih in političnih strukturah, kot ga je $\mathrm{v}$ ameriškem kontekstu med drugimi izpostavil Charles Mills, staroselci nenehno opozarjajo na svoje nezavidljivo mesto v avstralski družbi, zahtevajoč enake možnosti za dvig na družbeni lestvici, kot so dane večinskemu prebivalstvu. Poleg različnih oblik aktivizma pomembno vlogo v protestu staroselcev opravlja književnost.

\section{Poezija protesta}

Sodobno postkolonialno teoretiziranje literarnega protesta problematizira zgodnejša pojmovanja, ki so se osredotočala predvsem na kritiko nespremenljivih binarnih delitev evropocentričnega diskurza, ne pa tudi na koncept kontakta med kolonizatorjem in koloniziranim subjektom (Ashcroft, Griffiths in Tiffin 86), ali - kot to imenuje Sara Suleri ustvarjanja "posebne intimnosti", ki pri nestaroselskih subjektih generira občutek krivde in producira idejo o $"$ narodu, ki ne pripada niti kolonizatorju niti koloniziranim « (113). Skladno s splošno usmeritvijo sodobne postkolonialne teorije, kot jo med drugimi začrtujejo Homi Bhabha, Ngũgĩ wa Thiong'o, Bill Ashcroft in Achille Mbembe, bom v nadaljevanju pokazala, da avstralska staroselska poezija z izpodbijanjem vsiljenih binarnih epistemoloških kategorij sodeluje pri redefiniranju identitetnih konstruktov in gradi prostor za medkulturno razumevanje in komunikacijo. Torišče silnic, ki to preprečujejo, je namreč locirano $\mathrm{v}$ pojmu identitete in reprezentacije, kar neobhodno zahteva vrednostno

\footnotetext{
${ }^{8}$ Pred referendumom leta 1967 , ko so staroselske skupnosti postale avtonomne, je bila prodaja alkohola staroselcem prepovedana. Ta prepoved se je ukinila, ker so politično korektni vladni svetovalci zatrjevali, da med staroselci odvisnost od alkohola ni prav nič večja kot med belimi Avstralci, le da se staroselci opijajo v javnosti, belci pa za domačimi stenami, piše Adi Wimmer (glej Wimmer). Razloge za ukinitev prepovedi prodaje alkohola je najbrž treba pripisati kolonizatorjevi sistematični spodbudi za konzumiranje alkohola med staroselci za lastno opolnomočenje (Pearson 122).
} 
zaobrnitev izkrivljenih reprezentacij. Kot trdi Mbembe, postkolonialni upor prebiva v "dekolonizaciji podobe« (De Sousa Santos 14); rušenje mitizirane preteklosti in preživelih stereotipov, ki jih je kolonialni diskurz povzdignil $\mathrm{v}$ objektivna dejstva, je vsekakor temeljno določilo besedil avstralskih staroselskih avtorjev.

Romaine Moreton je v eni od svojih pesmi v zbirki Post Me to the Prime Minister (2004) zapisala: "Ni lahko biti črn / to življenje je v celoti politično« (111), v "Working Notes" pa takole: "Ustvarjati in ne prikazovati strahot rasizma na eni strani in lepot staroselske kulture na drugi bi zame pomenilo ustvarjati burkaška dela" (14). ${ }^{9}$ Da so njegova dela zamišljena $\mathrm{z}$ namenom preoblikovanja javnega mnenja, je med drugimi izpostavil tudi večkrat nagrajeni avstralski staroselski pesnik in dramatik Jack Davis (Chesson 191). Nedvomno lahko pritrdimo Adamu Shoemakerju, ki je že v osemdesetih letih prejšnjega stoletja poudaril, da je avstralska staroselska poezija v prvi vrsti poezija družbenega protesta (201). Nastala je kot integralni del organiziranega boja staroselcev za osvoboditev izpod navidezno zakoličenih okvirjev dominantnega diskurza (Slemon 107). S svojim ekspresivnim pogovornim glasom izraža zahtevo po odpravi krivic, ki so zaznamovale njihovo razmerje s kolonialno represijo. "Odpor proti določeni politiki ali pogojem «, kot Michael Lipsky definira protestno aktivnost (1145), je vsekakor njeno osrednje tematsko izhodišče in povezujoča nit, prav tako tudi prikazovanje družbene resničnosti, ki v bralcih izzove šok, skrb in politični dvom, kar kot pomembno značilnost protestne poezije izpostavlja Nicholas Coles (677). Slednje je še posebej značilno za pesniški izraz naše avtorice: njene deskripcije nasilja političnega sistema, od fizičnega terorja do psihičnega ponižanja in izničenja, bralce kar silijo $\mathrm{k}$ premisleku in pomembnim notranjim odločitvam. Zaradi poseganja $\mathrm{v}$ negativne identitetne fabrikacije staroselcev, ki predpostavljajo rasno inferiornost in izključenost iz enakovredne udeležbe $\mathrm{v}$ družbi, pa je njena poezija tudi sredstvo za revitalizacijo politične in kulturne identitete staroselcev.

Leanova je pesnica $\mathrm{z}$ nezmotljivim posluhom za tipične staroselske teme in s sposobnostjo povezati močno čustvo in kritično misel. $\mathrm{V}$ njenih pesmih, ki praviloma prinašajo avtobiografsko izkušnjo, se žalost in bolečina prepletata $\mathrm{z}$ jezo in razočaranjem nad neprekinjeno kronično revščino in zapostavljenostjo staroselcev. Pri obravnavi družbenih anomalij in pogumnem odstiranju procesov in logike, ki so njene ljudi obdržali v podrejenem položaju, jo vodita osebna prizadetost in

\footnotetext{
${ }^{9} \mathrm{O}$ poeziji Romaine Moreton med drugim pišem v Čerče. "Black Australia«.
} 
ustvarjalna nujnost. Poleg močnih argumentov prav ta srčna zavzetost zagotavlja intenziteto njenega pesniškega izraza in posledično čustveno odzivnost bralca. Čeprav so čustva konvencionalno v diametralnem nasprotju $\mathrm{z}$ argumentacijo, so pomembna sestavina protestne književnosti. Kot je izpostavila Patricia D. Netzley, wavtorji družbenega protesta vzpodbujajo bralca $\mathrm{k}$ empatiji s tistimi, ki trpijo zaradi določenega družbenega problema« (xiii). Leanova bralčevo čustveno angažiranost zagotovi tudi z različnimi pesniškimi prvinami, predvsem z retoričnimi vprašanji, satiričnimi antitezami in neposrednim nagovarjanjem tako nestaroselske kot staroselske bralne publike. Prvo poziva k ponovnemu pregledu zgodovine in premisleku o povezavi med glavnimi značilnostmi te zgodovine in sedanjo realnostjo, drugo spomni na bogato kulturno dediščino, na čas, »ko je bila vsa dežela ena sama kuhinja / in shramba nikoli prazna «10 (Leane, Dark Secrets 14).

Pesničino obujanje kolektivnega spomina na idilične čase in bogato staroselsko kulturo je še posebej pomembno, saj se »konektivna struktura" sleherne kulture vzpostavlja prav s kolektivnim spominom (Juvan, »Kulturni«386). Že Maurice Halbwachs je poudaril, da spomin ni samo odtis osebnih doživetij in zaznav, ampak je "prežet s kolektivnimi interferencami« (Juvan, »Kulturni« 385). Privzemamo in prek kolektivnega spomina namreč prenašamo tudi tisto, kar smo "dobili od drugih" (prav tam). Kolektivni spomin obstaja v duševnosti posameznikov, ki za zavedanje sebe potrebujejo drugega oziroma drugo zavest, ki jih prepoznava. Kot nas spomni Frantz Fanon, kolonizatorju ne zadošča samo nadzor nad sedanjostjo in prihodnostjo koloniziranih; z zanikanjem dostojanstva vredne kulture mora izkriviti tudi njihovo preteklost (Fanon, The Wretched 210) in takšno mitizirano podobo povzdigniti v zgodovinsko dejstvo. Kolonizirane družbe zato ne opisuje kot družbo, iz katere so izginile vse vrednote, ampak kot družbo, v kateri nikoli ni bilo vrednot (211). Prav tako kolonizatorju ni dovolj samo dejstvo dominantnega položaja; sprejeti ga mora tudi kolonizirani subjekt. Ekonomski in politični nadzor namreč ni učinkovit brez mentalnega nadzora. Nadzor nad kulturo neke skupnosti pomeni nadzor nad »orodji samoidentifikacije v razmerju do drugih" (Weaver 20), zato vladajoče kulture tipično delujejo na etnocentrični način $\mathrm{v}$ definiranju svoje identitete in identitete vseh drugih, ustvarjajoč iluzijo o svoji večvrednosti kot o neizpodbitnem dejstvu. Rehabilitacija zgodovinske in kulturne identitete koloniziranih zato pomeni iskanje "kolektivnega resničnega jaza, ki je skupen vsem

${ }^{10}$ Vse v tem članku navedene odlomke iz zbirke Temne skrivnosti je v slovenščino prevedla avtorica članka. 
$\mathrm{z}$ isto zgodovino in predniki« (Loomba 183). Kot je v pesmi "Zborno mesto "staroselce pozvala Leanova: "Poj spomin! Poj o tistem drugem času, / o vodah, žuboreč plemensko modrost. / Poj o tistem drugem svetu. / Poj o glasu drugega jezika, / o glasu mater, starih mater / [...] Poj spomin! Poj spomin! / Poj ... poj... poj... « (Leane, Dark Secrets 6).

Problematizacija naturaliziranih stereotipov kot vitalne strategije, $s$ katero je Evropa vzpostavila in obdržala svoj kolonialni diskurz (Bhabha, "The Other" 293), je pomembna tudi za odpravo "ponotranjene kolonizacije, " kot ponotranjeni kompleks staroselcev o svoji inferiornosti imenuje George Tinker (118). Opirajoč se na Heglovo teorijo o vzajemnem priznavanju, Fanon vzroke za to ponotranjeno stereotipno predstavo zatiranih pripisuje dejstvu, da slednji kot kolonialni subjekt $\mathrm{v}$ zgodovinskih odnosih $s$ kolonizatorjem niso bili deležni priznavanja drugega, kar predstavlja nujen predpogoj za samospoštovanje (Fanon, Black Skin 216). Individualna identiteta je namreč dislocirana in se konstituira $\mathrm{v}$ relaciji z drugim, ki ga omogoča in hkrati omejuje (Martin 100). Naloga staroselskih avtorjev je, da presežejo identitetni konstrukt staroselca kot "primitivnega drugega«, značilnega za evropsko stereotipno portretiranje staroselcev, izpostavijo pa njihovo "sinkretično, dinamično in adaptivno identiteto" ter mobilizirajo najrazličnejše strategije obsodbe, argumentacije in prepričevanja, je odločen Louis Owens (12). Poudarjanje bogate staroselske kulture in krepitev identitete staroselcev oziroma njihova "galvanizacija", kot to imenuje Mudrooroo, ${ }^{11}$ sta nedvomno pomembna aspekta Temnih skrivnosti in avstralske staroselske poezije nasploh.

Oglejmo si zdaj nekoliko natančneje, kako pesniška beseda naše avtorice opravlja svojo protestno in edukativno funkcijo. Niz dvaintridesetih pesmi te stremljivo zasnovane zbirke, ki že z naslovom nakazuje avtoričino osrednje tematsko črpališče, ${ }^{12}$ se napaja v legendah, anekdotah in družinskih zgodbah. Predvsem pa je to pripoved o uradni zgodovini z močnim vtisom duha skupnosti. Sega od idiličnih

${ }^{11}$ Narogin Nyoongah, bolj znan po imenu Mudrooroo, delo Kevina Gilberta Because a White Man'll Never Do It (1973) predstavi kot "klic k akciji in galvanizaciji staroselcev« (Brewster, »Engaging 72).

${ }^{12}$ Naslov zbirke se glasi: Dark Secrets: After Dreaming (AD) 1887-1961 (Temne skrivnosti: Po sanjski dobi (AD) 1887-1961). Kot je razložila pesnica, se izraz »temne skrivnosti« nanaša na staroselce. "Dreaming « je njihova osrednja filozofija, je čas, ko so duhovi njihovih prednikov ustvarjali svet. V prenesenem pomenu ga lahko razumemo kot obdobje njihove samobitnosti. Akronim AD pa ni okrajšava za "After Dreaming«, ampak za Anno Domini, s čimer pesnica aludira na prisilno pokristjanjevanje. Letnici se nanašata na rojstvo pesničine stare matere in rojstvo pesnice. 
opisov družinskega življenja plemenske skupnosti v obdobju njihove samobitnosti do mračnih uvidov v obdobje njihovega zatiranja. Pesmi so včasih samo kratke, trenutne opazke, prebliski, iztrgani iz konteksta, vedno pa posledica doživete bolečine. Nič nenavadnega torej, da zarežejo kot nož. Včasih se zdi, da se pesnica v svoji vnemi po razkrivanju mračne preteklosti ujame $\mathrm{v}$ zanke pretirane zgovornosti, kljub gostobesednosti pa je $\mathrm{v}$ njenih pesmih še veliko neizrečenega.

Liričnemu izlivu o prvinskem utripu življenjskih tokov, ljubezni do prednikov, nedoumljivih kozmičnih skrivnostih in tesni povezanosti ljudi z naravo v prvi pesmi sledi nepredvidljivo mreženje pretresljivih pričevanj o suženjstvu, konfinaciji in kolonializmu. V središču dogajanja so marginalizirani ženski glasovi, ki pogumno razgaljajo brutalnost in brezupnost kolonialne Avstralije, ki nima nič skupnega s popularnim mitom o deželi miru, priložnosti in blaginje: "Vdrli so v deželo $s$ svojimi ladjami / z boleznimi, pohlepnostjo in znanostjo, / prelivali so našo kri / nam oskrunili zemljo / posiljevali matere in zasužnjili otroke / vse to, da je naša zemlja danes raj / raj za volno, žito, delovno silo, bogastvo in belce" (Temne skrivnosti 11). Pri ubeseditvi nekaterih najbolj temačnih epizod avstralske zgodovine, ki zasenčujejo vse uspehe avstralske družbe, Leanova neprestano vzporeja obe kulturi in filozofiji. S poudarjanjem duhovne in emocionalne širine staroselcev - lastnosti, ki jim je omogočila preživetje $\mathrm{v}$ sovražnem, nemoralnem in emocionalno sterilnem belem okolju, pesnica oporeka ne samo napačnim, z miti obloženim predstavam belcev o staroselcih, ampak tudi predstavam belcev o njih samih. Skladno s tradicijo ustnega izročila za ta namen niza motiv za motivom, ki se v vsaki pesmi sestavljajo drugače, vsi pa imajo svoje izhodišče v dejstvih, zgodovini in pričevanjih, $\mathrm{v}$ iskanju in razkrivanju resnice. S svojim besedilnim svetom Leanova namreč preprečuje, da bi politične in kulturne identitetne fabrikacije o staroselcih ostale relevantna osnova za njihovo samoidentifikacijo, nevarnost, na katero opozori Arif Dirlik (429).

Da bi pri povezovanju sedanjosti s preteklostjo poudarila socialne in čustvene stiske enih in nebrižnost drugih, bralca pa prisilila v sodelovanje s podoživljanjem zgodovinskih travm, pesnica premišljeno uporablja prvo osebo. "Zaklenili so nas kot / temne skrivnosti. / Ne da bi slišali naš jok, / ne da bi videli našo bedo, / ne da bi čutili našo lakoto," je neusmiljena $\mathrm{v}$ bičanju kolonizatorjevega povsod opaznega izgubljenega občutka za sočloveka (Leane, Dark Secrets 14). Čeprav se upira samoljubnemu ukvarjanju z lastno bolečino, $v$ objektivno vzročno-posledično naracijo vpleta subjektivne, čustveno podprte resnice. Največ pozornosti nameni staroselski ženski, njeni siloviti moči in odpornosti 
tudi takrat, ko je najbolj zatirana. Socialno izvržena najde pribežališče in uteho $\mathrm{v}$ duševnem svetu, polnem toplote, nežnosti in ljubezni, kar je v diametralnem nasprotju s svetom plehkih vrednot belih žena. Te "varujejo svojo skromnost " pod sloji bledega blaga, čipk, naborkov, gumbov in pentelj, pod »znaki civilizacije, uspeha in uglajenosti«, je Leanova pikra v svojem posmehu (22). Ironičen posmeh na račun belih priseljenk je še posebej izrazit v pesmi "Breme belih žena. ${ }^{13}$ Uvodno lahkotno norčevanje spričo njihove neživljenjske konvencionalnosti se $\mathrm{v}$ nadaljevanju sprevrže $\mathrm{v}$ hiperbolično zajedljive tone:

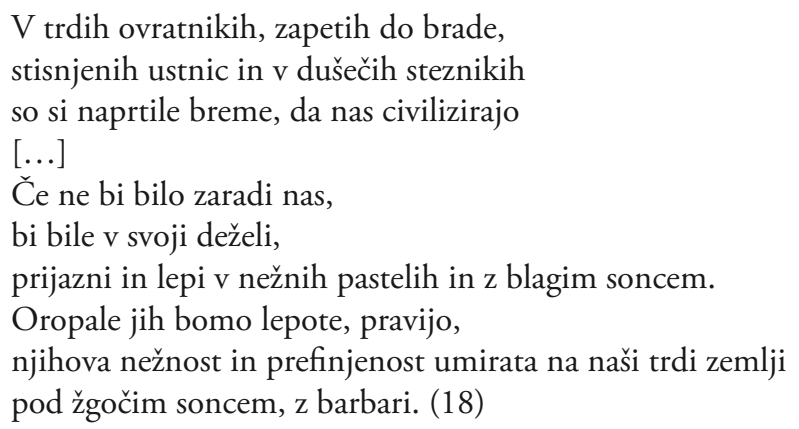

"Civiliziranje neciviliziranih", tipični kolonizatorjev izgovor za storjene grozote, je tema, ob kateri se pesničina mnogokrat preizkušena ironična drža še stopnjuje in kulminira v ugotovitvi »Srečo imamo, pravijo, da so prišli Angleži, / naši odrešitelji / in nas v imenu svojega Gospoda / izvlekli iz kulture kamene dobe, / pri tem pa bíli, kričali in ubijali« (15). $\mathrm{Z}$ nespregledljivo ironično subtilnostjo, ki ob značilnem direktnem načinu izpovedi pride še bolj do izraza, pesnica razkriva glavne družbene anomalije in obsoja ne samo namensko destrukcijo staroselcev, ampak tudi vsako obliko nasilja nad ljudmi. Za jezikovni zapis svoje kritike pesnica uporablja univerzalna slogovna sredstva, kot so podvojitve ali večkratno ponavljanje posameznih besed, besednih vrst in celih stavkov, številne metafore in domišljene kontraste med belim in črnim ter besednozvezne paradokse oz. oksimorone (npr. »bele nočne more«), ki se prepletajo, preigravajo in dopolnjujejo.

Kontrastno poigravanje $\mathrm{z}$ belo in črno ima še posebno moč v pesmi »Od bele do črne.« V prvi kitici pesnica $\mathrm{z}$ vztrajnim kopičenjem primere za primero ustvarja nostalgično predstavo življenja staroselcev pred prihodom belega agresorja: "Svet je bil barvit / rdeč kot kri in

${ }^{13}$ Naslov aludira na znano pesem Rudyarda Kiplinga "White Man's Burden" (»Breme belega človeka»), ki izraža prepričanje, da je belcem naložena naloga, da civilizirajo t. i. divjake. 
zemlja in ptica / moder kot voda in nebo in roža, / rjav kot okra in trava in žival ...» (12). Že kar igrivo vzdušje se z vztrajnim linearnim nizanjem nasprotij, ki se v gosti pripovedni mreži prepletajo $s$ spominskimi scenami, nenadoma prevesi $\mathrm{v}$ resne, temne tone:

Nič več rdeče, nič več modre, nič več rumene, zelene, škrlatne, oranžne ali rjave.

Nič več sive.

Samo črno in belo, samo belo in črno, samo dobri in zli, svobodni in ujeti, gospodar in suženj, bogat in reven, dober in slab, tisti, ki imajo, in tisti, ki nimajo, premožni in razlaščeni, mi in oni. (12)

Jezikovni spekter se tu in tam razširi z retoričnimi vprašanji, $s$ katerimi pesnica aludira na neodzivnost bele Avstralije, na lastnost, ki jo Mills imenuje »kognitivni hendikep belcev« (454), ko gre za priznavanje obstoja rasne diskriminacije in zatiranja:

"Zakaj nas je Bog ustvaril kot temne skrivnosti," stokajo moje sestre.

"Zakaj nas ni ohranil kot temne skrivnosti," sprašujem jaz.

Bili smo srečni, dokler neodkriti. (Leane, Dark Secrets 15)

Kot številnim drugim staroselskim avtorjem, ki v objektivni resničnosti ne najdejo zatočišča pred sencami preteklosti, umetniško ustvarjanje tudi Leanovi pomeni terapevtsko sredstvo obračuna in sprave s travmatičnimi spomini. Njene pesmi se velikokrat berejo kot deduktivno izpeljane analize, vztrajno nizanje argumentov pa se skoraj praviloma prevesi $\mathrm{v}$ temne tone. Kljub prevladujočim temnim barvam pa pesničina izpoved ne izzveni v pesimističnih akordih. Že omenjena slogovna sredstva namreč nimajo samo funkcije poročanja o navidezno nespravljivih razlikah in kaotičnosti neke dobe, ampak tudi kličejo $\mathrm{k}$ premisleku in spremembam. $\mathrm{V}$ odzivu na nasprotja $\mathrm{v}$ avstralski družbi pesnica daje prednost svobodnemu izrazu pred strogo pesniško obliko, trdno vztrajajoča na izhodišču, da obliko določa misel in ne obratno. Verzi so zato predvsem poetično obarvane povedi z globoko občutenimi vsebinami. Čeprav je v njenih pesmih manj prestopanja jezikovnih in pravopisnih omejitev v primerjavi s pisanjem nekaterih njenih sodobnikov, se ob branju vedno znova lahko prepričamo, da je za avtorico pomembna predvsem sporočilnost. Trdno opirajoča se na svoje staroselske korenine, kar je opazno tako v teksturi kot v dikciji in ritmu njene pesniške 
besede, in pozorna na svet okoli sebe, Leanova obtožuje »kolonizacijo védenja in biti«, kot Walter Mignolo označuje stanje brez "možnosti dostopa do znanja, razumevanja in obstoja« (391), s svojo kritiko pa prispeva k zavesti o nujnosti odprave takšnega stanja.

V tej poeziji najbrž ne bomo iskali presežne umetniške vrednosti; njena presežna vrednost je v kolektivnem dobrem za celotno družbo. $\mathrm{Z}$ izvorom $\mathrm{v}$ osebni izkušnji in globoko vtisnjeno kolektivno mislijo deluje kot mesto interpolacije politične in kulturne reprodukcije vzpostavljenih hierarhičnih odnosov in identitetnih konstruktov. $\mathrm{Na}$ tem mestu je prikladno omeniti sodobnega ameriškega staroselskega dramatika Williama Y. Roba, ki je ob neki priliki izjavil, da staroselci pišejo zato, da se opolnomočijo, da prevzamejo nadzor nad svojo preteklostjo, sedanjostjo in prihodnostjo (Pulitano 19). Povedano drugače, "pišejo zato, da lahko živijo«, kot je svojo študijo o ameriški staroselski književnosti naslovil Weaver (glej Weaver). To je vsekakor poslanstvo, ki ga uspešno opravlja tudi Leanova. Z ubeseditvijo nekaterih epizod $\mathrm{v}$ avstralski zgodovini, o katerih bi bela Avstralija raje še naprej prikladno molčala, avtorica razgalja družbenozgodovinsko realnost in intervenira $\mathrm{v}$ rasistično strukturo moči in stereotipne predstave dominantnega diskurza. $S$ tem prispeva k destabilizaciji avtoritete tistih, ki so do nedavnega imeli monopol nad predstavitvijo, med svojimi ljudmi pa oblikuje in krepi občutke osebnega in skupinskega ponosa in samozavesti. Zaradi velike osebne zavzetosti pri pisanju o tem, kaj v sodobni avstralski družbi pomeni biti črn, in z izbiro ustreznega pesniškega izraza je ustvarila delo, ki bele avstralske bralce ne le napeljuje k premisleku, ampak tudi evocira občutke nelagodja, dvoma in krivde.

Kljub zasidranosti $\mathrm{v}$ avstralskih razmerah pa njen pesniški svet ni prostorsko zamejen. Je namreč dokumentacija posledic kolonialne ekspanzije na vse tiste, ki jim je po logiki kolonizacije še vedno odvzeto dostojanstvo in katerih življenje ne ustreza humanim kriterijem moderne retorike. Osrednje težave, s katerimi se soočajo avstralski staroselci, »enake pravice, enake možnosti, boljša zdravstvena oskrba, boljša izobrazba, vse enako« (Brewster, O’Neill in Van Den Berg 189) so skupni številnim manjšinam $\mathrm{v}$ politično ohranjenem subalternem položaju, kar nas kar sili, da povlečemo vzporednice čez državne meje in pesničino kritiko prenesemo $\mathrm{v}$ kontekst svojih družbenih travm. Slovenci pri tem nismo nikakršna izjema. 


\section{Zaključek}

Identiteta se oblikuje znotraj specifičnih odnosov moči in ima konkretne družbeno-politične implikacije. Poseganje v identitetne konstrukte zato ni pomembno samo s stališča ponovne opredelitve in razkrivanja vzvodov preteklega zatiranja, ampak tudi s stališča snovanja novih okvirov medsebojnega delovanja. Konstruiranje identitet je tudi nenehen literarni proces. Kot »medij kulturnega spomina« književnost namreč opravlja pomembno »identitetno funkcijo « (Juvan, »Kulturni« 379). Identiteta avstralskih staroselcev se je vse od začetka kolonizacije do danes oblikovala $v$ različnih literarnih zvrsteh in žanrih, skoraj vedno pa $\mathrm{v}$ zavesti mainstreamskih avstralskih avtorjev. Ti so ideje in prakse staroselske kulture vrednotili s svojimi evropocentričnimi merili in na temelju neenake politične moči ustvarili in vzdrževali rasne stereotipe, ki so staroselcem onemogočili možnost avtonomne eksistence in jih izključili iz enakovredne participacije v avstralski civilizaciji.

$\mathrm{V}$ pričujočem prispevku smo zagovarjali trditev o »transformacijskih potencialih« literarnih besedil, kot Ashcroft imenuje možnost osvoboditve izpod navidezno neukinljivih binarnih nasprotij dominantnega diskurza s prilastitvijo dominantnih oblik reprezentacije in prevzemom nadzora nad samoreprezentacijo (Ashcroft, On Post-Colonial 112). Kot smo poskušali pokazati, je prav to tudi osrednja preokupacija avstralske staroselske književnosti. $Z$ razcvetom v osemdesetih letih prejšnjega stoletja reprezentacija staroselcev ni bila več izključno plod kulture, ki si je nadzor nad vsemi »drugimi« prisvojila tudi z degradacijo njihove zgodovine in s predpostavljeno rasno inferiornostjo. Zamišljena z namenom, da poda svojo naracijo zgodovinskih situacij, staroselska umetniška beseda spodbuja drugačna premišljevanja in destabilizira kontinuum bipolarne logike in spremljajoče identitetne hierarhije kot objektivnega dejstva. Z ozaveščanjem o medsebojni odvisnosti in nujnosti pozitivne interakcije med kulturami pa sodeluje pri ustvarjanju pogojev za drugačno, boljšo kvaliteto medsebojnih odnosov, za družbo, v kateri »različnost ne bo povezana z domnevno ali vsiljeno hierarhijo" (Bhabha, The Location 4). V današnjem turbulentnem času, ki ga zaznamuje ortodoksno vztrajanje na hierarhični delitvi kultur, je to še posebej pomembno. 


\section{LITERATURA}

Amir, Samir. Evrocentrizem: kritika neke ideologije. Prevod: Katja Kraigher. Ljubljana: Sophia, 2009.

Ashcroft, Bill, Gareth Griffiths in Helen Tiffin. The Empire Writes Back: Theory and Practice in Postcolonial Literatures. London: Routledge, 1989.

Ashcroft, Bill. On Post-Colonial Futures: Transformations of Colonial Culture. London; New York: Continuum, 2001.

Barbo, Matjaž. »'Tihi ton' estetike umetnostne religije«. Primerjalna književnost 38.2 (2015): 57-66.

Bhabha, Homi. "The Other Question: The Stereotype and Colonial Discourse«. Twentieth Century Literary Theory: A Reader. Ur. K. M. Newton. Palgrave, London: Macmillan Publishers Limited, 1997. 293-301.

Bhabha, Homi. The Location of Culture. London; New York: Routledge, 1994.

Brewster, Anne. "Engaging the Public Intimacy of Whiteness: The Indigenous Protest Poetry of Romaine Moreton ". Journal of the Association for the Study of Australian Literature (2008): 56-78.

Brewster, Anne, Angeline O'Neill in Rosemary Van Den Berg. Those Who Remain Will Always Remember: An Anthology of Aboriginal Writing. Fremantle: Fremantle Arts Centre Press, 2000.

Carter, David in Kay Ferres. "The Public Life of Literature». Culture in Australia: Policies, Publics and Programs. Ur. Tony Bennet in David Carter. Cambridge: Cambridge University Press, 2003. 140-160.

Coles, Nicholas. »Democratizing Literature«. College English 48 (1986): 64-80.

Chesson, Keith. Jack Davis: A Life Story. Melbourne: Dent, 1988.

Crow, Brian in Chris Banfield. An Introduction to Postcolonial Theatre. Cambridge: Cambridge University Press, 1996.

Čerče, Danica. »'Ko je bila vsa dežela ena sama kuhinja': sodobna avstralska lirika. Temne skrivnosti avstralske staroselske pesnice Jeanine Lreane». Delo (30. april 2013): 12.

Čerče, Danica. "Black Australia 'Writes Back' to the Literary Tradition of Empire." CLC Web: Comparative Literature and Culture 19.4 (2017). Splet.

Čerče, Danica. "Ideološko zaznamovana recepcija Steinbeckovih del v komunistični Vzhodni Evropi«. Jezik in slovstvo 63.1 (2018): 90-101.

De Sousa Santos, Boaventura. "Between Prospero and Calibari: Colonialism, Postcolonialism and Inter-identity". Luso-Brazilian Review 39.2 (2002): 9-43.

Dirlik, Arif. »Rethinking Colonialism: Globalisation, Postcolonialism and the Nation«, The International Journal of Postcolonial Studies 4.3 (2002): 428-448.

Fanon, Frantz. The Wretched of the Earth. Harmondsworth: Penguin, 1971.

Fanon, Frantz. Black Skin, White Masks. London: Pluto Press, 1986.

Foucault, Michel. Vednost-oblast-subjekt. Ljubljana: Krtina, 2008.

Gonzales, Madelena in Rene Agostini, ur. Aesthetics and Ideology in Contemporary Literature and Drama. Newcastle upon Tyne: Cambridge Scholars Publishing, 2015.

Guha, Ranajit. Dominance without Hegemony: History and Power in Colonial India. Cambridge: Cambridge University Press, 1998.

Hage, Ghassan. Against Paranoid Nationalism: Searching for Hope in a Shrinking Society. Annandale: Pluto Press, 2003.

Heiss, Anita, in Peter Minter, ur. Anthology of Australian Aboriginal Literature. Montreal: McGull-Queen's University Press, 2008.

Johnston, Tim. "Australia Says 'Sorry' to Aborigines for Mistreatment«. The New York Times (13. februar 2008). 
Juvan, Marko. Literarna veda v rekonstrukciji: uvodv sodobni študij literature. Ljubljana: LUD Literatura, 2006.

Juvan, Marko. »Kulturni spomin in literatura«. Slavistična revija 53.3 (2005): 379-400. Leane, Jeanine. Dark Secrets: After Dreaming (AD) 1887-1961. Berry, NSW: Press Press, 2010.

Leane, Jeanine.»Aboriginal Representation: Conflict or Dialogue in the Academy». The Australian Journal of Indigenous Education 39.1 (2010): 32-39.

Levine, George. "Reclaiming the Aesthetics». Falling into Theory: Conflicting Views on Reading Literatures. Ur. David Richter. New York: Bedford, 2000. 378-391.

Lipsky, Michael. „Protest as a Political Resource». The American Political Science Review 62.4 (1968): 1144-1158.

Loomba, Ania. Kolonializem in neokolonializem. Ljubljana: Orbis, 2009.

Lukács, György. History and Class Consciousness. Cambridge, MA: Massachusetts Institute of Technology Press, 1971.

Martin, James. »Identity«. Cultural Geography: a Critical Dictionary of Key Ideas. Ur. David Sibley, David Atkinson in Peter Jackson. London: I. B. Tauris, 2005. 97-102.

Mignolo, Walter. "On Subalterns and Other Agencies«. Postcolonial Studies 8.4 (2005): 381-407.

Mills, Charles. »Race and the Social Contract Tradition«. Social Identities 6.4 (2004): 441-462.

Moreton, Romaine. Post Me to the Prime Minister. Alice Springs: Jukurrpa Books, 2004.

Moreton, Romaine. »Working Notes.«How 1.5 (2001): 14.

Netzley, Patricia. Social Protest Literature: an Encyclopedia of Works, Characters, Authors, and Themes. Santa Barbara: ABC-CLIO, 1999.

Nowra, Louis. Bad Dreaming: Aboriginal Men's Violence Against Women and Children. North Melbourne: Pluto Press, 2007.

Owens, Louis. Other Destines: Understanding the American Indian Novel. Norman: University of Oklahoma Press, 1992.

Pearson, Julie. "Acts of Transfer: The 1975 and 1975 Productions of Raven and Body Indian«. Querying Difference in Theatre History. Ur. Scott Magelssen in Ann Haugo. Newcastle upon Tyne: Cambridge Scholars Publishing, 2007. 114-125.

Pulitano, Elvira. »Telling Stories Through the Stage: A Conversation with William Yellow Robe«. Studies in American Indian Literatures 10.1 (1998): 19-44.

Said, Edward W. Culture and Imperialism. New York: Vintage, 1994.

Shoemaker, Adam. Black Words, White Pages: Aboriginal Literature 1929-1988. St. Lucia: Queensland University Press, 1989.

Slemon, Stephen. »Unsettling the Empire: Resistance Theory for the Second World«. The Post-colonial Studies Reader. Ur. Bill Ashcroft, Gareth Griffiths in Helen Tiffin. London; New York: Routledge, 2003. 104-110.

Suleri, Sara. "The Rhetoric of English India«. The Postcolonial Studies Reader. Ur. Bill Ashcroft, Gareth Griffiths in Helen Tiffin. London; New York: Routledge, 2003. 111-113.

Sutton, Peter. "The Politics of Suffering: Indigenous Policy in Australia since the 1970s". Anthropological Forum 11.2 (2001): 125-173.

Tinker, George. Missionary Conquest. Minneapolis: Fortress Press, 1993.

Weaver, Jace. That the People Might Live: Native American Literatures and Native American Community. Oxford; New York: Oxford University Press, 1997.

Wimmer, Adi. »Autonomous Aboriginal Communities in Australia". Acta Neophilologica 42.1-2 (2009): 111-122. 


\section{The Reshaping of Identities in Dark Secrets by Australian Indigenous Poet Jeanine Leane}

Keywords: Australian literature / Indigenous poetry / Leane, Jeanine: Dark Secrets / cultural identity / cultural stereotypes / Eurocentrism

The article deals with the contemporary Australian Indigenous poetry, particularly with the verse of Jeanine Leane. Until very recently a marginalised voice in Australian literary studies, Australian Indigenous poetry has obtained an important role in the articulation of Indigenous peoples' political thought, successfully performing both educative and healing function. Constituting an indictment of white Australian racism, a recuperation of neglected Aboriginal history, and a call for change, Indigenous authors have become involved in the production that used to be reserved as the exclusive domain of Europeans. Based on the premise that literature can play an important role both in maintaining and disrupting the exercise of power, and written against the backdrop of critical whiteness studies, the article focuses on Leane's collection Dark Secrets (2010). It investigates how the poet uses her medium to explore various aspects of indigeneity and intervene in the public dynamics of racial separation. More specifically, it shows that, by challenging the ongoing reproduction of whiteness as a static privilege-granting category and system of dominance, and affirming Indigenous Australians' authentic rather than an imposed cultural personality, Leane's poetry performs personal and collective empowerment of Australian Indigenous peoples and represents an important site for the renegotiation of an inter-racial relationship.

1.01 Izvirni znanstveni članek / Original scientific article

UDK 821.111(94).09-1Leane J.

DOI: https://doi.org/10.3986/pkn.v43.i2.10 